\title{
Study on the stability of highway slope in cold region under freeze-thaw cycles
}

\author{
Hongyu Chen ${ }^{1, *}$ Xizhong Yuan ${ }^{1}$, and Wenbo Liu ${ }^{1}$ \\ ${ }^{1}$ Chang'an University, Highway College, 710064 Xi'an, China
}

\begin{abstract}
Based on thermo-mechanical coupling and elastoplastic theory, a finite element (FE) numerical simulation was adopted to study the stability of slopes in cold regions under freeze-thaw cycles. And the prediction of slope landslide was also studied through the calculation of strength reduction coefficients combination. The result shows that the development of the slope vertical displacement under freeze-thaw cycles can be divided into two stages: rapid stage and stable stage. After combining the two reduction coefficients of cohesion and internal friction of the soil, the maximum vertical displacement on the top of the slope in this region can be calculated as a reference for predicting the slope landslides. Meanwhile, the corresponding safety factor of the slope in the cold region can be obtained according to the reduction coefficients. .
\end{abstract}

\section{Introduction}

With the global warming, the instability and landslides of slopes in cold regions are gradually increasing [1]. Therefore, the research on the stability of frozen soil slopes in cold regions has become more and more important. The positive freezing landslides, positive thawing landslides, and freezing-thaw landslides are the main types of instability to slopes in cold regions, and thermal thawing is a common cause of slope landslides in cold regions [2,3]. Fujun Liu studied the development and deformation characteristics of landslides based on the engineering examples of slope thermal melt landslides in permafrost regions of the Qinghai-Tibet Plateau, and summarized the causes of slope landslides as external factors (man-made excavation, water flow, erosion) and internal factors (melting ice at the freeze-thaw interface) $[4,5]$.

The soil slopes in cold regions are subjected to the effects of repeated thawing settlement and frost heave under the temperature cycle, so that the strength of the slope soil is reduced and ultimately leads to instability $[6,7]$. Freeze-thaw in the temperature cycle only occurs in the soil in the seasonal active layer, for which the traditional slope stability analysis method is not suitable. Aiming at the highway slope in the frozen soil area of the Greater Khingan Mountains, a finite element (FE) multiphysics simulation software was used to establish an elastic-plastic thermo-mechanical coupled slope model. The displacement field of the slope under freeze-thaw cycles was analysed, and its sliding process was discussed.

\section{Theory}

The moisture in the frozen soil slopes will transfer under the alternating temperature of cold and warm year after year. In warm seasons, the slope begins to melt and the moisture content increases as the temperature rises, which reduces the shear strength of the sliding surface, resulting in a sharp decline in the stability of the slope. Under repeated freezing and thawing, the moisture content of the soil increases. When the voids between the soil particles are completely filled with water, the stress between the soil particles decreases, thus reducing the cohesion and shear strength of the soil.

Under the action of long-term freeze-thaw cycles, the mechanical parameters of soil change to varying degrees. Researchers found through laboratory experiments that the soil cohesion and internal friction angle damage coefficients would gradually decrease with the increasing number of freeze-thaw cycles. After 10 freeze-thaw cycles, the damage coefficient and the shear strength of the soil both tend to be stable [6].

\section{Models}

\subsection{Geometric model and parameters}

Comprehensively considering the relationships among strength parameters, time and temperature, a FE thermalmechanical coupling model of frozen soil slope is established to study the instability process caused by the decline in strength of the slope after freezing and thawing cycles.

The geometric model is shown in Figure 1, where the gradient of the slope is 1 .

\footnotetext{
" Corresponding author: 2018121150@chd.edu.cn
} 


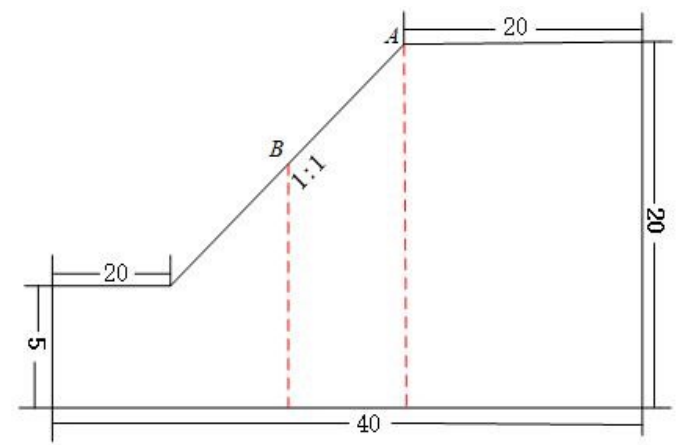

Fig. 1. Slope geometry.

The relationship between mechanical parameters of frozen soil and temperature in cold area is defined as [8]:

$$
\begin{gathered}
\mathrm{E}=a_{1}+b_{1} T^{0.6} \\
v=a_{2}+b_{2} T \\
\mathrm{c}=a_{3}+b_{3} T \\
\varphi=a_{4}+b_{4} T
\end{gathered}
$$

where E presents the modulus; $v$ presents Poisson's ratio; c presents the cohesion; $\varphi$ presents the angle of internal friction; $a_{i}$ and $b_{i}$ are the test parameter, and the values of each number in the model is shown in Table 1.

Table 1. Mechanical parameters of the soil.

\begin{tabular}{|c|c|c|c|c|c|c|c|}
\hline $\mathrm{a}_{1}$ & $\mathrm{~b}_{1}$ & $\mathrm{a}_{2}$ & $\mathrm{~b}_{2}$ & $\mathrm{a}_{3}$ & $\mathrm{~b}_{3}$ & $\mathrm{a}_{4}$ & $\mathrm{~b}_{4}$ \\
\hline 20 & 27 & 0.3 & -0.008 & 0.024 & 0.09 & 12.5 & 0.6 \\
\hline
\end{tabular}

The relationship between initial moisture content and soil strength is [9]:

$$
C=\mathrm{A}+\mathrm{B} \mathrm{w}^{\mathrm{c}}
$$

In the formula (5), A, B and c all present experimental parameters, and in the model of this paper, $\mathrm{A}=0.0208, \mathrm{~B}$ $=1.2054 \mathrm{E}-11$, and $\mathrm{c}=7.5578$. The thermophysical parameters of the soil in different water comtent are shown in Table 2 [10].

Table 2. Thermophysical parameters of the soil in different moisture content.

\begin{tabular}{|c|c|c|c|c|c|}
\hline$w(\%)$ & $\rho_{d}$ & $C_{u}$ & $C_{f}$ & $\lambda_{u}$ & $\lambda_{f}$ \\
\hline 15 & 1830 & 2200 & 1880 & 0.94 & 0.95 \\
\hline 17 & 1800 & 2320 & 1950 & 1.01 & 1.07 \\
\hline 19 & 1890 & 2500 & 2020 & 1.09 & 1.20 \\
\hline
\end{tabular}

where $w$ presents the soil moisture content; $\rho_{d}$ presents the dry density of soil; $C_{f}$ represents the heat capacity of the soil at positive temperature; $C_{u}$ represents the heat capacity of the frozen soil; $\lambda_{u}$ represents the heat transfer coefficient of the soil at positive temperature; $\lambda_{f}$ represents the heat transfer coefficient of the frozen soil.

\subsection{Boundary conditions}

The annual average air temperature in the Greater Khingan Mountains is $-5^{\circ} \mathrm{C}$ to $0^{\circ} \mathrm{C}$. In this paper, considering that the annual average temperature in the northeast of China is increasing year by year, the temperature and surface temperature are calculated with the following function [11-14]:

$$
\begin{gathered}
T_{\mathrm{a}}=T_{\mathrm{M}}+\mathrm{A} / 2 \sin (2 \pi t / 365)+0.05 t / 360 \\
T_{\mathrm{s}}=1.1939 T_{\mathrm{a}}+1.3182
\end{gathered}
$$

where $T_{\mathrm{a}}$ presents the air temperature; $T_{\mathrm{M}}$ presents annual average temperature; $t$ presents the time in days; A presents the range of temperature throughout the year; $T_{\mathrm{s}}$ presents the surface temperature of the slope.

\section{Results and discussion}

\subsection{Slope stability}

Slope landslide is affected by many factors, such as the moisture content of the soil, the shear strength and the cohesion of the soil, the grade of the slope, etc. First of all, assuming that the moisture content of the soil is $15 \%$, the process and causes of the slope landslide are analysed from the results of the stress field through FE numerical calculation.

When the FE numerical simulation analysis is not convergent, it is deemed that the slope has been slumped under this condition. Figure 2 and Figure 3 respectively show the slope stress distribution when the slope is unstable.

The maximum tensile stress on the top of the slope is $55 \mathrm{kPa}$, while the maximum compressive stress inside the slope is $330 \mathrm{kPa}$, which is at the lower part of the slope. Figure 4 shows the effective plastic strain distribution.

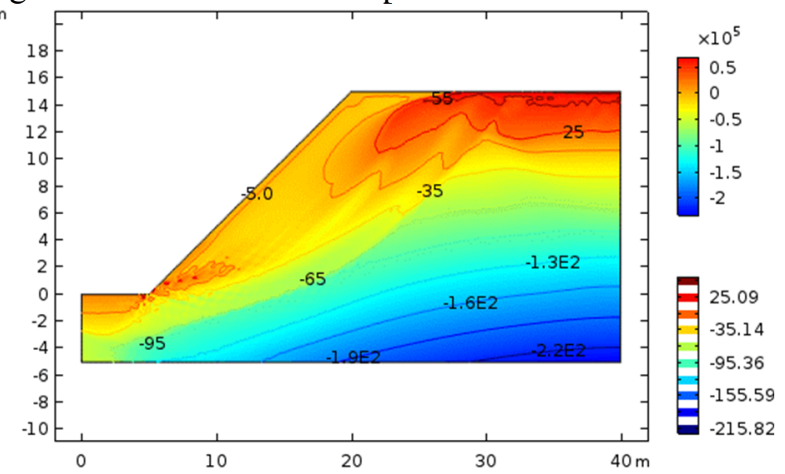

Fig. 2. Maximum principal stress distribution.

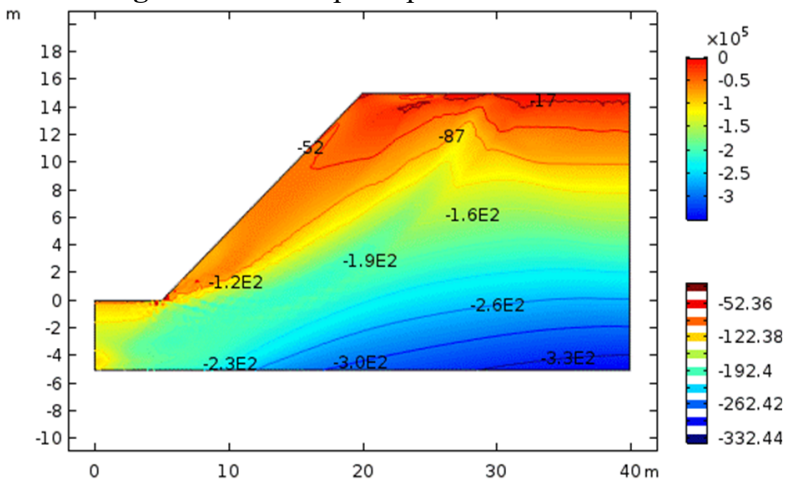

Fig. 3. Minimum principal stress distribution. 


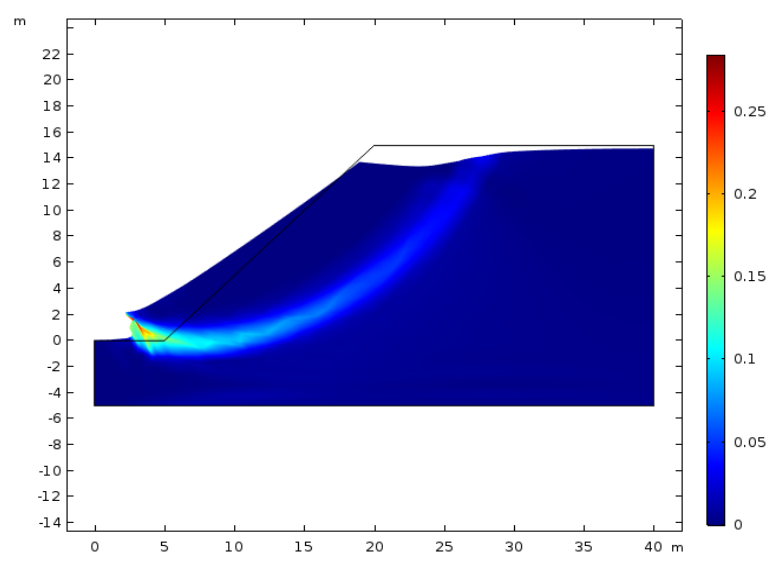

Fig. 4. Effective plastic strain distribution.

Figure 5 shows the vertical displacement of the point A (on the top of the slope) and the point B (on the surface of the slope) over time. The changing trend of the vertical displacement of point $A$ and point $B$ in a freeze-thaw cycle is basically the same, which can be divided into a rapid stage and a stable stage. Specifically, as the temperature gradually rises, the seasonal active layer will gradually melt and the moisture content of the soil will increase, resulting in a sharp drop in the strength of the soil, which is the cause of the rapid development of the vertical displacement of point A and B. After entering the cold season, the active layer of the slope gradually freezes, and the shear strength of the soil increases significantly with the decrease in temperature. During this period, the development of the vertical displacement at points $\mathrm{A}$ and B slow down.

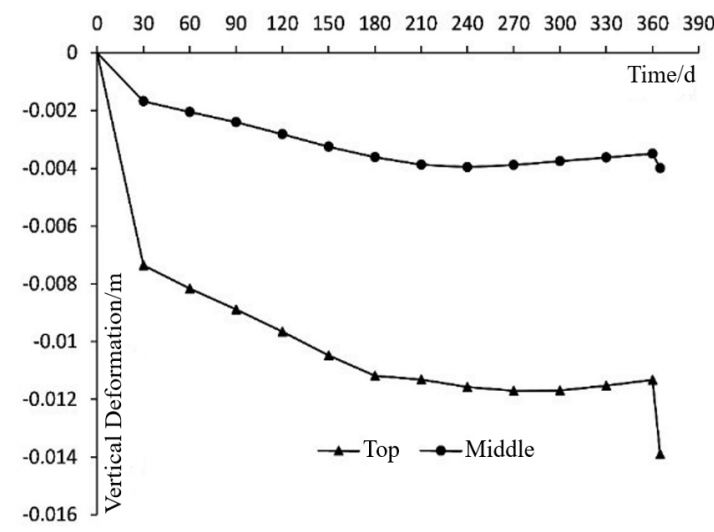

Fig. 5. Vertical displacement with a moisture content of $15 \%$.

In addition, the influence of different water content of the two soil bodies is also analysed. Figure 6 and Figure 7 show the vertical displacement of points $\mathrm{A}$ and $\mathrm{B}$ when the soil moisture content is $17 \%$ and $19 \%$, respectively. For a slope with a soil moisture content of $17 \%$, it eventually landslide after 8 repeated freezing and thawing. For a slope with a soil moisture content of $19 \%$, it can maintain long-term stability.

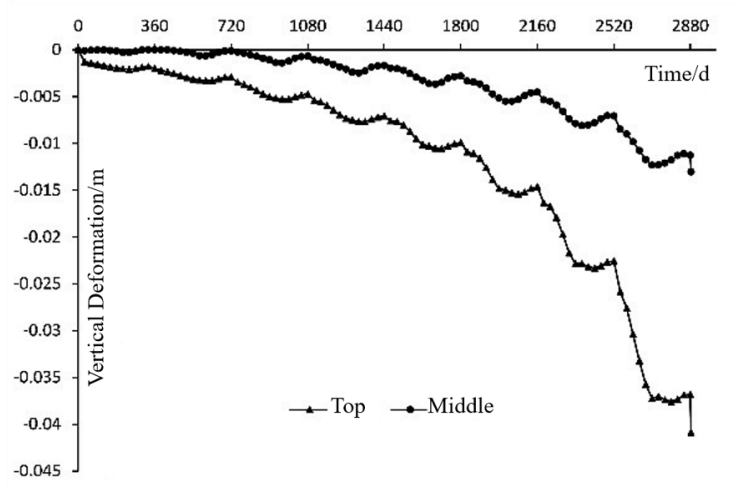

Fig. 6. Vertical displacement with a moisture content of $17 \%$.

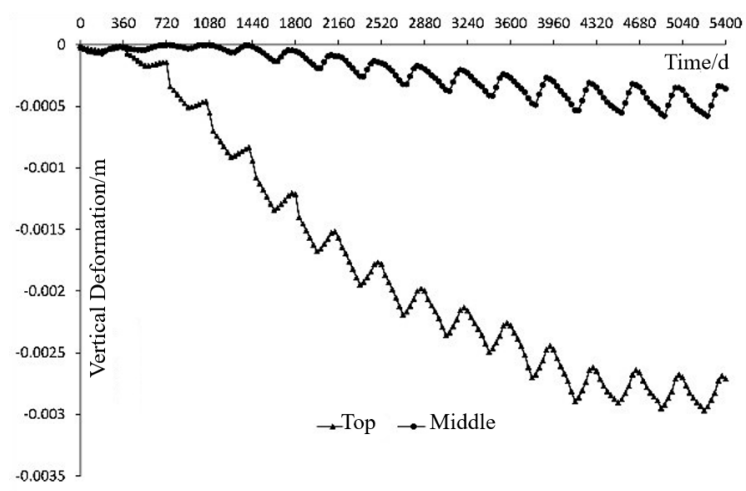

Fig. 7. Vertical displacement with a moisture content of $19 \%$.

\subsection{Slope stability prediction}

The strength reduction method is mainly used to judge whether the slope has slide based on two aspects: the change of the vertical displacement, the extent of the plastic zone. First, set an initial strength reduction factor and bring it into the model for calculation. If the calculation result shows that the slope is still in a stable state, increase the strength reduction factor and recalculate. When the reduction factor increases to a certain value, the slope begins to slide, so the reduction factor at this time can be regarded as the safety factor of the slope. The strength after reduction is expressed as:

$$
\begin{gathered}
\mathrm{C}_{\mathrm{F}}=\mathrm{C} / F_{1} \\
\varphi_{\mathrm{F}}=\tan ^{-1}\left[\tan \left(\varphi / F_{2}\right)\right]
\end{gathered}
$$

where $C_{F}$ presents the cohesion of the soil after reduction; $C$ presents the initial cohesion; $\varphi_{F}$ presents the internal friction angle of the soil after reduction; $\varphi$ represents the internal friction angle; $F_{1}$ presents the reduction coefficient of cohesion, and $F_{2}$ represents the reduction coefficient of internal friction angle.

$F_{l}$ was selected to 12 different values at equal intervals from 1 to $1.52 . F_{2}$ was selected to 12 different values at equal intervals from 1 to 1.57 . Then combine different $F_{l}$ and $F_{2}$ into 114 different strength reduction coefficients combinations, and then bring each combination into the model for calculation.

Figure 8 shows the vertical displacement of the point A calculated by 114 combinations of reduction coefficients. It can be seen from the figure that before $F_{l}$ increases to 1.45 , the vertical displacement continues to 
increase with the increasement of $F_{1}$ and $F_{2}$. After $F_{1}=$ 1.47 and $F_{2}=1.55$, the displacement does not continue to increase, because the calculation of the model does not converge, and the slope begins to landslide. At this time, the maximum vertical displacement is $42.68 \mathrm{~mm}$. Therefore, it can be considered that when the vertical displacement of point $\mathrm{A}$ is less than or equal to $42.68 \mathrm{~mm}$, the slope is safe, and $42.68 \mathrm{~mm}$ is the displacement at which the slope is in a critical state of landslide.

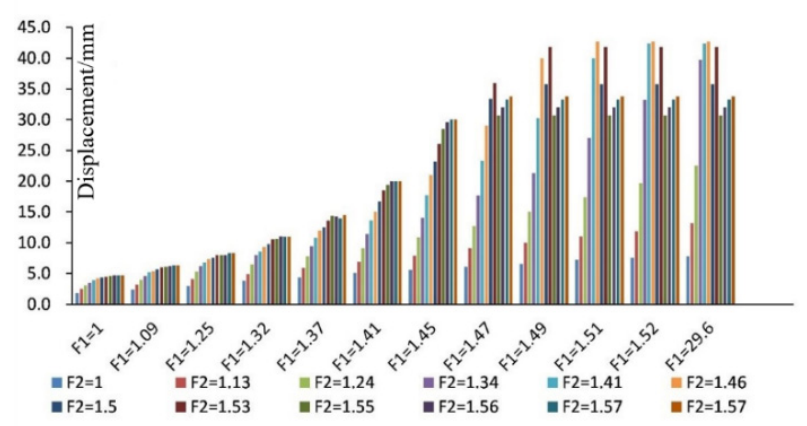

Fig. 8. Vertical displacement of point A under different combinations of reduction coefficients.

\section{Conclusion}

Aimed at the stability of slopes in cold areas, this paper used FE multiphysics simulation software to establish an elastic-plastic thermo-mechanical coupled slope model, and analysed the displacement under several freeze-thaw cycles, and use the combination of reduction coefficients to obtain the maximum displacement before the slope failure.

Through the calculation results, the full article can be summarized as follows:

- Under the freeze-thaw cycles, the vertical displacement curve of the slope in the cold area with time is like a step, which can be divided into a rapid development stage and another stable development stage.

- The FE numerical calculation shows that the moisture content of the slope soil has a great influence on the stability of the slope.

- By combining the reduction coefficients of cohesion and internal friction angle into the FE model for calculation, the maximum vertical displacement before the slope landslide can be obtained, which can be used to predict the landslide.

\section{Acknowledgments}

Authors are very grateful to Penghui Chen and Yaguang Yuan for their help and valuable discussions in the method of this paper.

\section{References}

1. Li, D.S. Wen, Z. Luo, J. Zhang, M.L. Chen, B. Sci. Total Environ. 694, 133547 (2019)

2. Kumsar, H.A. Mec. Roches 33 (1), 31-51 (2000)

3. Niu, F.J. Cheng, G.D. Lai, Y.M. Jin, D.W. Chin, J.
Geotech. Eng 26 (3), 402-406 (2004)

4. Niu, F.J. Luo, J. Lin, Z. Cold Reg. Sci. Technol. 8384 (15), 131-138 (2012)

5. Niu, F.J. Luo, J. Lin, Z. Jpn. Landslide Soc. 13 (1), 111 (2016)

6. Gao, Q. Wen, Z. Wang, D.Y. Niu, F.J. Xie, Y.L. Gou, Y.T. Rock Soil Mech. 39 (08), 2814-2822 (2018)

7. Srikrishnan, S.S. Tatsuya, I. Tetsuya, T. Eng. Geol. 221, 154-169 (2017)

8. Yu, L.L. Xu, X.Y. Qiu, M.G. Yan, Z.L. Li, P.H. Rock Soil Mech. 31 (08), 2448-2452(2010)

9. Lu, Z. Xian, S.H. Yao, H.L. Fang, R. She, J.B. Cold Reg. Sci. Technol. 157, 42-52 (2019)

10. Xin, L.C. Ma, W. Xu, Z.L. Xu, X.Y. Wang, J.L. Code for engineering geological investigation of frozen ground (China Planning Press, Beijing, 2014)

11. Li, S.Y. Zhang, M.Y. Zhang, S.J. Huang Z.J. J. Glacio. 'Geocry. 5, 860-867 (2008)

12. Yang, Y. Liu, H.P. Wang, Z.G. Yin, W.C. Zang, W.L.Y. Ge, Q. Heilongjiang Gongcheng Xueyuan Xuebao, Ziran Kexueban. 31 (01), 15-18 (2017)

13. Zhao, S.C. Luo, Y. J. Meteo. Env. 23 (3), 1-4 (2016)

14. Yuan, X.Z. Li, N. Zhao, X.Y. Rock Soil Mech. 31 (10), 3265-3273 (2010) 